\title{
GOVERNMENT AGAINST THE TERRORIST THREAT OF TWENTY FIRST CENTURY
}

\author{
James M. Smith and William S. Thomas, eds., The Terrorism Threat and the U.S. \\ Government Response: Operational and Organizational Factors \\ (Colorado Springs, CO: USAF Institute for National Security Studies, 2001), \\ <http://www.usafa.af.mil/inss/terrorism.htm>
}

\begin{abstract}
fter the end of the Cold war, slowly but surely, the terrorism threat established -itself on the top of the US national security agenda. Before September 11th that may have not been obvious to the outside observer. For the national security community, however, it seems that that was considered ground truth, the proof being reflected in this book.
\end{abstract}

Published in the spring of 2001, this compendium treats extensively the terrorist threat, the issues of preemption, prevention, deterrence and denial of terrorism actions, and organizational factors of the US governmental response to terrorism.

Although twelve authors contribute their own chapters, they all seem to agree that terrorism is "calculated violence applied toward coercive intimidation or provocation" with two central differentiating factors: "dedication to a political cause" and "instrumental reliance on violence." Further adhering to the classical works of David Fromkin, the authors agree that terrorism "achieves its goal not through its acts but through the response to its acts. ... terrorist actions aim at psychological result. But even that psychological result is not the final goal. Terrorism is violence used in order to create fear; but it is aimed at creating fear in order that the fear, in turn, will lead somebody else — not the terrorist — to embark on some quite different program of action that will accomplish whatever it is that the terrorist really desires."

The book provides detailed analysis of the shift in the terrorist threat. Out of this analysis we shall underline three points:

- Ever stronger combination of a political objective with ethnic and religious components;

- $\quad$ Shift from violence measured to fit a political agenda to increased lethality associated with a total, holy war; 
- Shift from a state sponsorship to a marriage of terrorism with organized crime and drug cartels, leading to "privatization of terror."2

In part I, to this general analysis of the changing nature of terrorism, the contributors present more focused investigation of the potential terrorist use of weapons of mass destruction and cyber threats.

Four contributions in part II focus respectively on preemption of terrorist threats, combating international terrorism, antiterrorism via counterproliferation, and the role of intelligence and force protection.

Part Three would be of highest interest to the readers of this special issue of Information \& Security. Recognizing the primary role of law enforcement in the fight against terrorism, the authors provide detailed analysis of the role of the military and of the State Department. Their analysis is based on existing legislation and experience, prudently distinguishing between prevention, response, and consequence management, as well as between domestic and international terrorism-quite a challenging endeavor given the ever blurring boundaries between the two.

One example of the complexity of the issue is the debate in Chapter 10. William Thomas provides meticulous analysis of current legislation and distinguishes not only between law enforcement and the military, but also among various branches of the military. Listing the twelve Emergency Support Functions (ESF) provided by FEMA: $^{3}$ (1) transportation; (2) communications; (3) public works and engineering; (4) firefighting; (5) information and planning; (6) mass care; (7) resource support; (8) health and medical services; (9) urban search and rescue; (10) hazardous materials; (11) food; and (12) energy, Thomas points out roles of various active, reserve and National Guard units.

The book is explicitly focused on experience, practices, organization and challenges to US Government. Nevertheless, it certainly is of value to policy makers and experts from other countries, as well as to those from intergovernmental and some nongovernmental organizations.

Ironically, published only a few months prior to September 11th, the book refers to Al-Qaeda and bin Laden in its introductory sentences, listing the terrorist and his organization first among the new terrorist threats. And as often happens, it proves that academics are often too optimistic. In chapter 9 the author calls for “... developing information and analysis that enables us to better predict how, when, and where the terrorists will strike because we have fed them the information on which they will likely act." ${ }^{, 4}$

In a complex world exact prediction is problematic, if not entirely impossible. There are no easy answers to terrorism. This book, and—unfortunately—life itself, confirms 
that. What is needed is a complex answer including, among others, legislative, procedural, and organizational changes, innovative use of technology, and new levels of international cooperation.

Books like this one definitely contribute to the search for answers. We look forward to volumes like this one, accounting for the tragic experience of September 11th and the response of the United States and the international community of democratic nations.

Andrey Todorov

\section{Notes:}

1 James M. Smith and William S. Thomas, Chapter Two: The Terrorist Threat in Strategic Context.

2 Ibid.

3 William S. Thomas, Chapter 10: The Military's Response to Domestic WMD Terrorism.

$4 \quad$ Peter S. Probst, Chapter 9:Intelligence and Force Protection vs Terrorism. 